\title{
A INFLUÊNCIA DOS SABERES DOCENTES NA ESCOLHA DE ESTRATÉGIAS DE ENSINO DOS ESPORTES COLETIVOS NO ESTÁGIO DE 6 AO 9 ANO
}

\author{
Patricia Machado da Silva \\ Universidade Federal de Pelotas, Pelotas, Rio Grande do Sul, Brasil \\ Mario Renato Azevedo Júnior \\ Universidade Federal de Pelotas, Pelotas, Rio Grande do Sul, Brasil
}

\begin{abstract}
Resumo
O objetivo foi identificar as estratégias de ensino de esportes coletivos utilizadas por estudantes no estágio supervisionado do $6^{\circ}$ ao $9^{\circ}$ ano de duas universidades federais e verificar o que influenciou nessa escolha: disciplinas, experiências esportivas pré-formação profissional e/ou as experiências de ensino durante a formação inicial. Realizaram-se estimulação da recordação, entrevista e análise dos Projetos Pedagógicos de Curso. Metade dos estagiários optou por métodos mais tradicionais. Todas as variáveis estudadas influenciaram nas escolhas didáticometodológicas dos estagiários. As disciplinas do curso de graduação e as experiências de prática docente parecem auxiliar na ressignificação dos saberes produzidos nas experiências préformação profissional.
\end{abstract}

Palavras-chave: Educação Física. Formação Inicial. Ensino dos Esportes. Saberes Docentes.

THE INFLUENCE OF TEACHER'S KNOWLEDGE IN THE CHOICE OF TEACHING STRATEGIES OF COLLECTIVE SPORTS IN THE INTERNSHIPS FROM $6^{\text {TH }}$ TO $9^{\text {TH }}$ YEAR

\begin{abstract}
The objective was to identify the teaching strategies of collective sports used by students in the supervised internships of the $6^{\text {th }}$ to $9^{\text {th }}$ year of two Federal Universities and to verify what influenced this choice: disciplines, sports experience, pre-training and/or teaching experiences during the initial training. A stimulation of the recall, interview and analysis of the Pedagogical Projects of Course was carried out. Half of the trainees opted for more traditional methods. All variables studied influenced the didactic-methodological choices of trainees. The disciplines of the undergraduate course and the experiences of teaching practice seem to help in the re-signification of the knowledge produced in the pre-vocational training experiences.
\end{abstract}

Keywords: Physical Education. Undergraduate. Teaching of Sports. Teacher's Knowledge. 


\section{LA INFLUENCIA DE LOS SABERES DOCENTES EN LA ELECCIÓN DE ES- TRATÉGIAS DE ENSEÑANZA DE LOS DEPORTES COLECTIVOS EN LA ETAPA DE $6^{\circ}$ AL $9^{\circ}$ AÑ}

\section{Resumen}

El objetivo fue identificar las estrategias de enseñanza de los deportes colectivos utilizadas por estudiantes en la práctica supervisada del $6^{\circ}$ a $9^{\circ}$ año de dos universidades federales y verificar lo que influencio en esa elección: disciplinas, experiencias deportivas pré-formación profissional y/o las experiencias de enseñanza durante la formación inicial. Se realizó estimulación del recuerdo, entrevista y análisis de los Proyectos Pedagógicos de Curso. La mitad de los aprendices optó por métodos más tradicionales. Las disciplinas del curso de graduación y las experiencias de práctica docente parecen auxiliar en la resignificación de los saberes producidos en las experiencias pre-formación profesional.

Palabras Clave: Educación Fisica. Formación Inicial. Enseñanza de los Deportes. Saberes Docentes.

\section{Introdução}

O ensino dos esportes coletivos (EC) tem ocorrido através do método tradicional, pelo qual se acredita que a técnica aprendida de maneira descontextualizada possibilitará uma aplicação com eficiência no jogo (SANTANA et al., 2015). No entanto, esse método tem sido questionado pela ênfase na técnica e no rendimento esportivo (COSTA; NASCIMENTO, 2004). De acordo com estudos realizados por Santana et al. (2015) e Freire Júnior, Maldonado e Silva (2017), embora existam diferentes abordagens, os professores continuam adotando um método tradicional para o ensino dos EC.

Para modificar esse ensino tradicional, diversos autores elaboraram propostas de ensino dos EC. Reverdito e Scaglia (2009), quando analisam os principais autores em Pedagogia do Esporte, percebem que, nas abordagens inovadoras, o processo de ensino dos EC é orientado para a compreensão do jogo a partir do desenvolvimento cognitivo (tática), junto da especificidade técnica. Isto só ocorrerá a partir de um processo contextualizado, isto é, utilizando o jogo como ferramenta indispensável à iniciação e ao treinamento dos EC, pois jogar se aprende jogando (REVERDITO; SCAGLIA, 2009).

A formação inicial em Educação Física é um momento significativo para a construção do conhecimento didático-metodológico, por isso se torna importante investigar como esse processo ocorre no âmbito das aulas de Educação Física $(\mathrm{EF})$ na escola em relação às estratégias pedagógicas empregadas no ensino dos EC. Existem muitos fatores que influenciam a forma como o professor pensa e atua.

Diante do exposto e sendo o EC o conteúdo mais trabalhado nas aulas de EF (FORTES et al., 2012; COSTA; NASCIMENTO, 2006), o objetivo desta pesquisa foi o de identificar as estratégias de ensino de esportes coletivos utilizadas por estudantes de Licenciatura em Educação Física no estágio supervisionado do $6^{\circ}$ ao $9^{\circ}$ ano de duas universidades federais do sul do Rio Grande do Sul. Além disso, identificar o que influenciou na escolha da estratégia: disciplinas, experiências de ensino durante a formação inicial e/ou experiências pré-formação profissional.

\section{Metodologia}

Este estudo se caracteriza como uma pesquisa descritiva, pois busca "a descrição das características de determinada população ou fenômeno ou, então, o estabelecimento de rela- 
ções entre as variáveis" (GIL, 2002, p. 42). Além disso, apresenta delineamento de casos múltiplos, já que estuda profundamente alguns poucos casos, procurando reunir ampla quantidade de informações sobre eles (THOMAS; NELSON, 2003).

Participaram da pesquisa quatro alunos dos cursos de Licenciatura em EF noturno de duas Instituições de Ensino Superior (IES) da rede federal do Sul do país (dois de cada universidade), que estavam realizando estágio supervisionado de $6^{\circ}$ ao $9^{\circ}$ ano. Para fins de identificação das IES, elas foram tratadas pelas letras A e B, conforme a ordem com que foi realizada a coleta de dados. As duas IES foram definidas como lócus da pesquisa devido às marcantes diferenças na estrutura curricular dos cursos de Licenciatura em EF, pois a instituição A oferece as disciplinas de EC e de ensino dos esportes de forma optativa e, na IES B, elas são obrigatórias. A partir de uma hipótese inicial, tal diferença poderia levar à escolha das estratégias a serem utilizadas e a uma prática pedagógica diferenciada entre os estagiários dessas duas universidades.

Foram observados três critérios para que os sujeitos pudessem ser selecionados: estar matriculado na disciplina de estágio supervisionado do $6^{\circ}$ ao $9^{\circ}$ ano; estar desenvolvendo algum conteúdo de EC durante o estágio, e permitir a gravação das aulas de estágio. A professora regente de cada turma decidiu se o estagiário deveria seguir seu planejamento ou se ele poderia escolher o conteúdo que achasse adequado - esta última situação ocorreu com três dos estagiários. Na IES A, inicialmente cinco alunos aceitaram participar, no entanto, três desistiram durante a coleta de dados. Já na IES B, três concordaram com a proposta do estudo, mas em uma escola não foi possível conseguir a autorização por escrito de todos os pais de alunos da turma de estágio.

Foram utilizadas as seguintes técnicas de coleta de dados: a) pesquisa documental, através da análise dos Projetos Pedagógicos de Curso (PPC) das duas IES quanto à presença de disciplinas de EC, disciplinas de metodologia de ensino dos EC, seja como disciplinas obrigatórias, seja como optativas; b) estimulação da recordação (ER), que consiste na gravação em vídeo da aula ministrada pelo estagiário e, posteriormente, a visualização da aula gravada junto ao sujeito da pesquisa (AMADO; VEIGA SIMÃO, 2013) - neste momento foram realizados questionamentos através de um roteiro semiestruturado que guiou o investigador, com questões sobre seus objetivos e estratégias de ensino escolhidas; c) entrevista semiestrutura$\mathrm{da}-\mathrm{o}$ entrevistador seguiu um roteiro padronizado. O roteiro continha 14 questões que abordaram as disciplinas de EC e de ensino de EC cursadas, as experiências esportivas préformação profissional e as experiências como professor de EC durante a graduação.

Em um primeiro momento, foi enviada uma carta de apresentação para as direções dos cursos de EF das IES selecionadas, requisitando a oportunidade de realização do estudo. Após o consentimento dessas instituições, foram solicitados os PPCs aos respectivos coordenadores. Em seguida, foi feita a seleção dos sujeitos e apresentados a eles os objetivos e os procedimentos da investigação. Todos assinaram o Termo de Consentimento Livre e Esclarecido (TCLE). As Secretarias Municipais de Educação de cada cidade receberam uma carta solicitando a autorização para a realização do estudo nas escolas municipais, explicando os objetivos e garantindo o anonimato dos alunos e das escolas. Uma das secretarias solicitou que todos os alunos envolvidos assinassem o TCLE para que pudessem ser feitas as filmagens das aulas dos estagiários. Diante disso, todos os discentes das duas turmas envolvidas na coleta em Pelotas assinaram o TCLE.

Cada estagiário teve quatro aulas gravadas por meio de uma câmera de vídeo digital e as imagens foram armazenadas em um microcomputador, tendo um total de $10 \mathrm{~h}$ de filmagem. Após a gravação de cada aula, a pesquisadora realizava a análise do vídeo a fim de identificar questões relacionadas ao ensino dos EC a serem perguntadas ao estagiário. Então, em um outro momento, em uma sala da IES em que ele estava matriculado, a filmagem era exibida pela pesquisadora para o sujeito. 
A ER foi conduzida a partir do roteiro estruturado e das questões elaboradas após a análise da gravação. $\mathrm{O}$ estagiário tinha liberdade para tecer os comentários que julgasse apropriados sobre suas ações. Esse processo foi realizado quatro vezes com cada um dos sujeitos da pesquisa, correspondendo a cada uma das aulas gravadas. Ao final da última ER, foi realizada a entrevista com cada um dos estagiários, que foi conduzida a partir do roteiro semiestruturado. Todas as ER e as entrevistas foram registradas por um gravador de voz e transcritas com o auxílio de um editor de textos. Posteriormente, as transcrições foram encaminhadas aos estagiários para que eles confirmassem as informações declaradas. O projeto foi aprovado pelo comitê de ética sob o parecer de $\mathrm{n}^{0}$ 1.540.567. As etapas dos procedimentos metodológicos estão representadas na Figura 1.

Figura 1: Organograma dos procedimentos metodológicos por etapas

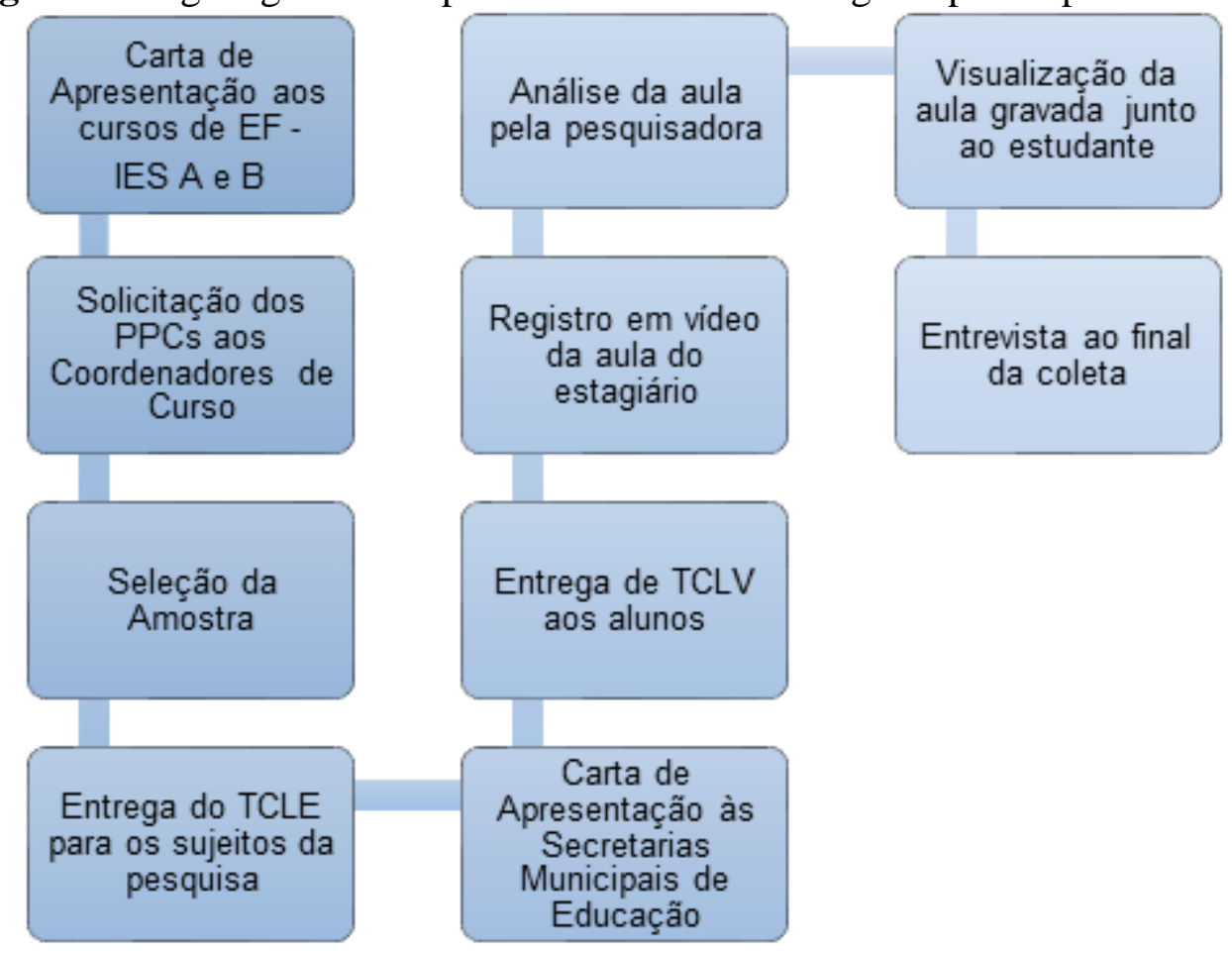

Fonte: Os autores, 2016.

A técnica de análise de conteúdo de Bardin (1977) foi conduzida envolvendo três fases: a) pré-análise: foi o momento em que ocorreram a organização e a leitura geral das informações disponíveis nas três fontes: PPCs, ER e entrevistas; b) exploração do material: a partir de uma leitura mais aprofundada, ocorreu a transformação dos dados brutos por seleção e agregação de trechos apropriados à pesquisa (BARDIN, 1977); c) tratamento e interpretação dos dados: as informações foram alocadas em categorias definidas previamente, sendo elas: intervenção realizada no estágio e estratégias utilizadas; disciplinas de esporte coletivo e de ensino dos esportes; experiências esportivas pré-formação profissional, e experiências de prática docente durante a formação inicial.

Para a análise das atividades utilizadas pelos estagiários, adotaram-se as estratégias apresentadas por Paes, Montagner e Ferreira (2015) para a classificação: exercício analítico, exercício sincronizado, brincadeira, jogo pré-desportivo, situação de jogo, jogo reduzido e jogo formal. Essa forma de classificar as atividades propostas baseia-se nos tradicionais métodos de ensino (analítico e global), porém, de fácil entendimento e operacionalização (PAES; MONTAGNER; FERREIRA, 2015). 
Após esse momento, realizou-se a interpretação dos dados a partir do embasamento teórico, com a finalidade de estabelecer relações entre os dados obtidos e os objetivos da pesquisa. Os estagiários da IES A foram identificados pelos números e letras $1 \mathrm{~A}$ e $2 \mathrm{~A}$ e os da IES B, pelos números e letras 3B e 4B, garantindo seu anonimato.

\section{Resultados e discussão}

\section{Intervenção realizada no estágio e estratégias utilizadas}

No texto a seguir, em um primeiro momento, se encontram contextualizadas as turmas dos sujeitos e, em seguida, são apresentados os objetivos das aulas e as estratégias de ensino dos EC utilizadas. O estagiário 1A era responsável por uma turma de $6^{\circ}$ ano, com 30 alunos, que não tinha conhecimento sobre o handebol, modalidade trabalhada por ele. O sujeito $2 \mathrm{~A}$ era responsável por uma turma de $8^{\circ}$ ano com 32 alunos e, assim como o anterior, trabalhou com handebol em uma classe que não conhecia esse esporte. O estagiário $3 \mathrm{~B}$ era responsável por uma turma de $7^{\circ}$ ano com 20 alunos. O conteúdo trabalhado foi o basquetebol, que já havia sido visto no $6^{\circ}$ ano de maneira superficial, de acordo com os próprios alunos. O estagiário $4 \mathrm{~B}$ era responsável por um $8^{\circ}$ ano com 21 alunos que desconheciam a modalidade ensinada, hóquei. Com a finalidade de facilitar o entendimento dos resultados, no Quadro 1 foram apresentadas as informações relativas aos objetivos de cada uma das quatro aulas filmadas de cada estagiário e as estratégias de ensino dos esportes utilizadas por eles.

Quadro 1: Objetivos das aulas e estratégias de ensino dos esportes coletivos utilizadas

\begin{tabular}{|c|c|c|c|c|c|}
\hline \multirow{2}{*}{\multicolumn{2}{|c|}{ Categorias }} & \multicolumn{4}{|c|}{ Estagiários } \\
\hline & & $1 A^{*}$ & $2 A^{*}$ & $3 B^{*}$ & $4 B *$ \\
\hline \multirow{4}{*}{$\begin{array}{l}\text { Objetivo de } \\
\text { cada aula e } \\
\text { estratégias } \\
\text { utilizadas }\end{array}$} & $\begin{array}{c}1^{\mathrm{a}} \\
\text { aula }\end{array}$ & $\begin{array}{l}\text { Vivenciar e avaliar a } \\
\text { técnica. } \\
\text { Estratégias: JR e JF. }\end{array}$ & $\begin{array}{l}\text { Trabalhar arremes- } \\
\text { so. Estratégias: } \\
\text { EA e SJ. }\end{array}$ & $\begin{array}{l}\text { Ensinar o passe e o } \\
\text { drible. } \\
\text { Estratégia: EA e } \\
\text { JPD (3) }\end{array}$ & $\begin{array}{l}\text { Aprimorar técnica. } \\
\text { Estratégias: ES (3) e } \\
\text { JR. }\end{array}$ \\
\hline & $\begin{array}{c}2^{\mathrm{a}} \\
\text { aula }\end{array}$ & $\begin{array}{l}\text { Sair da rotina. } \\
\text { Estratégias: ES e JF }\end{array}$ & $\begin{array}{l}\text { Não sair tanto para } \\
\text { marcar. } \\
\text { Estratégias: } \quad \text { SJ } \\
\text { (2). }\end{array}$ & $\begin{array}{l}\text { Retomar o conteúdo } \\
\text { da aula anterior. } \\
\text { Estratégias: JPD }\end{array}$ & $\begin{array}{l}\text { Trabalhar a técnica. } \\
\text { Estratégias: BR e JF. }\end{array}$ \\
\hline & $\begin{array}{c}3^{\mathrm{a}} \\
\text { aula }\end{array}$ & $\begin{array}{l}\text { Relembrar fundamen- } \\
\text { tos. } \\
\text { Estratégias: JR e JF. }\end{array}$ & $\begin{array}{l}\text { Observar se apli- } \\
\text { cam o que já foi } \\
\text { visto. Estratégias: } \\
\text { JR }\end{array}$ & $\begin{array}{l}\text { Ensinar drible e o } \\
\text { arremesso. Estraté- } \\
\text { gias: EA, ES e BR. }\end{array}$ & $\begin{array}{l}\text { Trabalhar a técnica e } \\
\text { cobranças de falta. } \\
\text { Estratégias: JF }\end{array}$ \\
\hline & $\begin{array}{c}4^{\mathrm{a}} \\
\text { aula }\end{array}$ & $\begin{array}{l}\text { Avaliar a técnica. } \\
\text { Estratégias: ES e JF. }\end{array}$ & $\begin{array}{l}\text { Trabalhar ataque. } \\
\text { Estratégias: SJ }\end{array}$ & $\begin{array}{l}\text { Trabalhar o passe } \mathrm{e} \\
\text { o arremesso. } \\
\text { Estratégias: ES, JR } \\
\text { e BR }\end{array}$ & $\begin{array}{l}\text { Trabalhar com siste- } \\
\text { mas e a marcação } \\
\text { individual } \\
\text { Estratégias: JF }\end{array}$ \\
\hline \multicolumn{2}{|c|}{$\begin{array}{c}\text { Estratégias } \\
\text { utilizadas nas } 4 \text { au- } \\
\text { las* }\end{array}$} & $\begin{array}{l}-2 \mathrm{ES} \\
-2 \mathrm{JR} \\
-4 \mathrm{JF}\end{array}$ & $\begin{array}{l}-1 \mathrm{EA} \\
-1 \mathrm{JR} \\
-4 \mathrm{JF}\end{array}$ & $\begin{array}{l}-2 \mathrm{EA} \\
-2 \mathrm{ES} \\
-1 \mathrm{JR} \\
-2 \mathrm{BR} \\
-4 \mathrm{JP}\end{array}$ & $\begin{array}{l}-3 \mathrm{ES} \\
-1 \mathrm{JR} \\
-1 \mathrm{~B} \\
-3 \mathrm{JF}\end{array}$ \\
\hline
\end{tabular}

* Estratégias de ensino segundo Paes, Montagner e Ferreira (2015): Exercício Analítico (EA), Exercício Sincronizado (ES), Jogo Reduzido (JR), Jogo Pré-Desportivo (JPD), Brincadeira (BR), Jogo Formal (JF) e Situação de Jogo (SJ)

Fonte: Os autores, 2017.

Em resumo, percebe-se no Quadro 1 que as escolhas metodológicas foram bem distintas. O estagiário 1A optou por métodos mais tradicionais (SANTANA et al., 2015), tendo em vista a utilização do jogo formal em todas as suas aulas. Além disso, utilizou-o na tentativa de 
avaliar o nível técnico de seus alunos e relembrar fundamentos técnicos. Já o sujeito 2A utilizou-se em grande parte das aulas de situações de jogo, em atividades de "ataque x defesa", com o número regulamentar de jogadores de handebol. Ainda, usou o exercício analítico para ensinar fundamentos técnicos e, a partir das situações de jogo, também procurou ensinar elementos dos sistemas defensivo e ofensivo.

$\mathrm{O}$ estagiário 3B foi o que mais diversificou as estratégias utilizadas. O estagiário 4B acredita que, para jogar hóquei, primeiro os alunos devem aprender a técnica. Ele, assim como o estagiário 1A, optou por um ensino mais tradicional (SANTANA et al., 2015). Ele utilizou o jogo formal para ensinar sistemas e marcação individual.

A intervenção dos estagiários 1A e 4B se assemelha aos resultados encontrados por Ramos, Graça e Nascimento (2006) em um estudo em que foram descritas as atividades utilizadas por três estagiários para o ensino do basquetebol. De maneira semelhante, houve a predominância do ensino dos fundamentos técnicos fora do contexto de jogo nas aulas de dois desses estagiários.

Essa abordagem é conhecida como tradicional e está presente nas aulas de EF desde os anos 60. A intervenção dos alunos 1A e 4B baseada nessa abordagem parece estar um pouco distante do que se acredita hoje na Pedagogia do Esporte. Existe uma crítica a esse modelo devido à dificuldade que o aluno terá em transferir os gestos aprendidos através de exercícios para o jogo formal. Além disso, essa abordagem pode dificultar o entendimento do EC e levar à desmotivação dos alunos devido aos exercícios pouco interessantes (COSTA; NASCIMENTO, 2004).

Graça e Mesquita (2002), em estudo de revisão sobre a evolução da investigação do ensino dos EC, evidenciam que as atividades de aprendizagem devem estar adequadas às exigências dos EC, na qual as tarefas abertas predominam. Logo, as atividades mais adequadas devem conter problemas que exijam que o aluno transforme o seu conhecimento (técnica) a fim de responder aos problemas (tática) impostos pelo ambiente, diferentemente do que ocorre nos exercícios, nos quais o aluno responde a uma situação totalmente previsível (estável, única e imposta previamente). Dessa maneira, a prática de fundamentos técnicos deveria ocorrer dentro do contexto de jogo.

Paes, Montagner e Ferreira (2015), assim como outros autores, sugerem a inserção do jogo na iniciação esportiva. Ele deveria ser tratado como um recurso pedagógico de grande relevância no ensino e na aprendizagem dos EC, pois facilita a compreensão da lógica do esporte, pode contribuir para a formação integral do aluno e provoca a tomada de decisão diante de diversas situações, assim como ocorre com o EC:

O jogo, além de imprevisível, possibilita o desafio, a motivação e a participação. Apresenta constantes problemas que exigem respostas criativas e hábeis, individuais e coletivas, o que, consequentemente, estimula a cooperação e importantes construções coletivas - para o jogo e para a vida. Permite ainda, ao aluno, compreender a complexidade dos jogos coletivos, de forma autônoma, inclusiva e diversificada (PAES; MONTAGNER; FERREIRA, 2015, p.13).

Entretanto, isso não quer dizer que o uso de exercícios deva ser excluído da iniciação esportiva. Galatti et al. (2014, p.157) dizem que "o problema está na prevalência destes exercícios em detrimento de estratégias de ensino que privilegiem a inteligência do jogador em relação ao jogo e ao sistema que o envolve". Notou-se na intervenção dos estagiários $2 \mathrm{~A}$ e $3 \mathrm{~B}$ tanto a utilização de exercícios, como também de jogos. Tendo o primeiro preferido atividades em situação de jogo, o segundo diversificou bastante o ensino através de brincadeiras, de jogos pré-desportivos e do jogo reduzido, utilizando-os com a finalidade de ensino e aprimoramento da técnica. 
Uma única abordagem não é suficiente para o ensino das habilidades técnicas e táticas, devido à complexidade dos EC. Diante disso, é necessário que o professor tenha conhecimento das diferentes estratégias, para que ele possa utilizá-las de acordo com seus objetivos e necessidades da turma (FERREIRA; GALATTI; PAES, 2005; COSTA; NASCIMENTO, 2004).

Em um estudo sobre os conhecimentos prévios de alunos ingressantes na faculdade de $\mathrm{EF}$, a preocupação com o desenvolvimento da técnica como requisito para jogar apareceu entre os entrevistados (RAMOS et al., 2014). O estagiário 4B pensa de maneira muito semelhante: "Sim, eles querem jogar, só que para jogar eles precisam aprender os fundamentos. E não adianta, senão não sai jogo".

Os métodos tradicionais entendem que o aprendizado dos gestos é um requisito mínimo para a atuação no jogo (GRAÇA; MESQUITA, 2002; DIETRICH; DÜRRWÄCHTER; SCHALLER,1984). Entretanto Graça (1998) afirma que a técnica se adquire a partir de uma especialização das habilidades motoras, das quais o aluno já tem um certo domínio, portanto, é esse controle mínimo das habilidades motoras que vai permitir a sua participação no jogo. Logo, não há, nesse sentido, justificativa para o predomínio de atividades com ênfase na técnica.

\section{Disciplinas de esportes coletivos e de ensino dos esportes}

Esta categoria tem a pretensão de descrever aspectos do currículo das duas IES e apresentar as disciplinas optativas de EC e de ensino dos esportes cursadas durante a graduação pelos estagiários. Após a análise dos dois currículos, pode-se perceber que a estrutura curricular em relação às disciplinas esportivas e às de metodologia de ensino dos EC das instituições A e B são diferentes.

A IES B apresenta disciplinas de EC (Futsal I, Futebol I, Handebol I, Voleibol I e Basquetebol I) e de ensino dos esportes (Pedagogia do Esporte) como obrigatórias. Além disso, em caso de interesse do aluno, é possível aprofundar o conhecimento nestes conteúdos através de disciplinas optativas de EC (Basquetebol II, por exemplo). Já a instituição A oferta todas as disciplinas de EC e de ensino dos esportes (Iniciação aos Esportes Coletivos) de forma optativa. Através da entrevista, foi possível obter informações sobre as disciplinas cursadas pelos estagiários, as quais serão apresentadas a seguir.

Figura 2: Disciplinas optativas cursadas pelos estagiários e estratégias de ensino dos esportes coletivos utilizadas por eles.
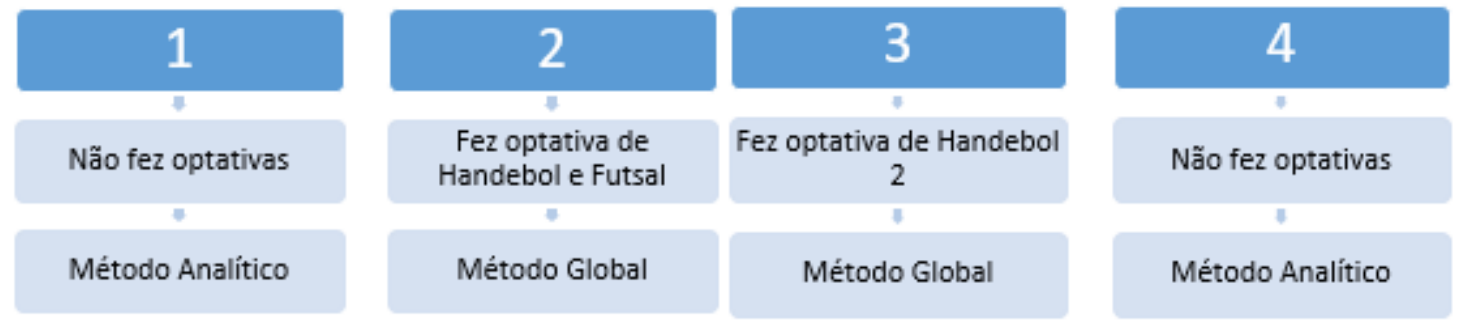

Fonte: Os autores, 2017.

Foi possível perceber que a IES A conta com uma maior diversidade de modalidades esportivas em seu currículo, sendo que todas elas são optativas, enquanto a B tem um aprofundamento dos EC de forma optativa, além das disciplinas de EC e de ensino do EC de forma obrigatória.

Os estagiários $1 \mathrm{~A}$ e $4 \mathrm{~B}$, que optaram por um método mais tradicional, foram os mesmos que não cursaram nenhuma disciplina optativa. Por outro lado, o $2 \mathrm{~A}$ e o $3 \mathrm{~B}$ utilizaram jogos e também fizeram as optativas de EC. O estagiário 3B, que fez escolhas metodológicas 
de forma bem variada, ainda conta com as disciplinas de EC e a de metodologia do ensino dos EC, pois são obrigatórias no currículo da universidade B, assim como para o estagiário 4B.

Dessa maneira, percebe-se que as disciplinas de EC parecem ter um efeito importante nas escolhas metodológicas dos estagiários. Essa possível influência das disciplinas pode ser percebida na fala do estagiário $2 \mathrm{~A}$ :

[...] boa parte das aulas práticas, eu tiro também das aulas práticas que a gente teve aqui, né. [...] Eu pego leituras com ele (professor da disciplina de Handebol), [...] mas as leituras com ele são mais técnicas, assim, né, de como ensinar a técnica, de como ensinar a tática do jogo. E a parte mais pedagógica do esporte coletivo e tudo o mais, eu acabo pegando o material daqui (disciplinas cursadas). (Estagiário 2A)

Tardif (2010), ao tentar identificar quais saberes os professores utilizam em seu trabalho e como são adquiridos, propôs um modelo tipológico apresentado no Quadro 2. Esses saberes são plurais e heterogêneos, vindos de diversas fontes e de diferentes momentos da vida do professor, sendo definidos como:

É necessário precisar também que atribuímos à noção de "saber" um sentido amplo que engloba os conhecimentos, as competências, as habilidades (ou aptidões) e as atitudes dos docentes, ou seja, aquilo que foi muitas vezes chamado de saber, de saber-fazer e de saber-ser. Essa nossa posição não é fortuita, pois reflete o que os próprios professores dizem a respeito de seus próprios saberes (TARDIF; RAYMOND, 2000, p.212).

Quadro 2: Saberes docentes dos professores

\begin{tabular}{|l|l|l|}
\hline Saberes dos professores & Fontes sociais de aquisição & $\begin{array}{l}\text { Modos de integração no } \\
\text { trabalho docente }\end{array}$ \\
\hline $\begin{array}{l}\text { Saberes pessoais dos profes- } \\
\text { sores }\end{array}$ & $\begin{array}{l}\text { A família, o ambiente de vi- } \\
\text { da, a educação no sentido } \\
\text { lato, etc. }\end{array}$ & $\begin{array}{l}\text { Pela história de vida e pela } \\
\text { socialização primária }\end{array}$ \\
\hline $\begin{array}{l}\text { Saberes provenientes da for- } \\
\text { mação escolar anterior }\end{array}$ & $\begin{array}{l}\text { A escola primária e secundá- } \\
\text { ria, os estudos pós- } \\
\text { secundários não especializa- } \\
\text { dos, etc. }\end{array}$ & $\begin{array}{l}\text { Pela formação e pela sociali- } \\
\text { zação pré-profissionais }\end{array}$ \\
\hline $\begin{array}{l}\text { Saberes provenientes da for- } \\
\text { mação profissional para o } \\
\text { magistério }\end{array}$ & $\begin{array}{l}\text { Os estabelecimentos de for- } \\
\text { mação de professores, os es- } \\
\text { tágios, os cursos de recicla- } \\
\text { gem, etc. }\end{array}$ & $\begin{array}{l}\text { Pela formação e pela sociali- } \\
\text { zação profission de formação nas insti- } \\
\text { tues pro- } \\
\text { fessores }\end{array}$ \\
\hline $\begin{array}{l}\text { Saberes provenientes dos } \\
\text { programas e livros didáticos } \\
\text { usados no trabalho }\end{array}$ & $\begin{array}{l}\text { A utilização das "ferramen- } \\
\text { tas" dos professores: progra- } \\
\text { mas, livros didáticos, cader- } \\
\text { nos de exercícios, fichas, etc. }\end{array}$ & $\begin{array}{l}\text { Pela utilização das "ferra- } \\
\text { mentas" de trabalho, sua a- } \\
\text { daptação às tarefas }\end{array}$ \\
\hline $\begin{array}{l}\text { Saberes provenientes de sua } \\
\text { própria experiência na profis- } \\
\text { são, na sala de aula e na esco- } \\
\text { la }\end{array}$ & $\begin{array}{l}\text { A prática do ofício na escola } \\
\text { e na sala de aula, a experiên- } \\
\text { cia dos pares, etc. }\end{array}$ & $\begin{array}{l}\text { Pela prática do trabalho e } \\
\text { pela socialização profissional }\end{array}$ \\
\hline
\end{tabular}

Fonte: Tardif (2010, p. 63).

Um dos saberes que integra a prática docente é o da formação profissional para o magistério, que são conhecimentos presentes na sociedade, selecionados pela IES e ofertados para os estudantes (TARDIF, 2010). Portanto, as disciplinas, incluídas nesta categoria, são 
saberes importantes para a formação inicial, pois são por onde o futuro professor tem contato com os conhecimentos específicos da área, de forma a prepará-lo para o trabalho.

Nesse sentido, Nascimento et al. (2009), em estudo que procurou abordar algumas iniciativas adotadas para assegurar a formação didático-pedagógica nos esportes, relatam sobre a inserção de disciplinas que tratam do ensino dos EC a fim de garantir um ensino mais adequado dos EC. Isto foi notado na intervenção do estagiário 3B, que cursou essa disciplina obrigatória. Entretanto, o mesmo não ocorreu na intervenção do estagiário 4B, o que pode ser resultado dos seus saberes pessoais e dos provenientes da formação escolar anterior.

O estagiário $1 \mathrm{~A}$ escolheu ministrar handebol durante o estágio, mesmo não tendo feito essa disciplina. Figueiredo (2004, p.108), quando questiona uma aluna do $5^{\circ}$ período, na mesma situação, sobre como e por que escolher o conteúdo sem ter tido contato com ele durante a formação, obteve a seguinte resposta: “' '[...] busquei lá trás em minhas vivências mesmo e o que eu via e o que eu vi depois. Mas aqui mesmo não, porque eu estava ingressando nas optativas' (Aluna do $5^{\circ}$ período/entrevista individual)". Muito provavelmente, o estagiário $1 \mathrm{~A}$ buscou em suas memórias sobre as aulas de EF como ensinar handebol, o que pode explicar a adoção de métodos tradicionais.

O conhecimento advindo da escola se mantém sólido durante a graduação e, como resultado, poucas são as mudanças em relação às suas crenças do modo de ensinar, já que a formação inicial não consegue enfraquecê-lo ou transformá-lo. E, quando se tornam docentes, se remetem a essas representações, o que leva à reprodução de comportamentos de seus antigos professores, pois eles trazem essa experiência de quando eram alunos na educação básica (TARDIF, 2010). Os professores passaram boa parte da vida inseridos no seu futuro local de trabalho e isso interioriza certezas, crenças e conhecimentos sobre a prática pedagógica, construindo sua identidade pessoal (TARDIF; RAYMOND, 2000). Sob o mesmo ponto de vista, isso pode explicar a escolha por um método mais tradicional de ensino dos EC pelo estagiário 4B.

\section{Experiências esportivas pré-formação profissional e de prática docente durante a for- mação inicial}

Nesta categoria, foram evidenciadas as experiências anteriores à formação inicial dos estagiários, como nas aulas de $\mathrm{EF}$ e em equipes escolares ou não escolares, tendo como foco as estratégias utilizadas no ensino dos EC por seus professores e treinadores. Também serão relatadas as experiências de prática docente dos alunos durante a formação inicial, como a participação em projetos de extensão, equipes ou projetos fora da universidade.

Figura 3: Experiências esportivas pré-formação profissional, de prática docente durante a formação inicial e as estratégias de ensino dos esportes coletivos utilizadas por eles no estágio 

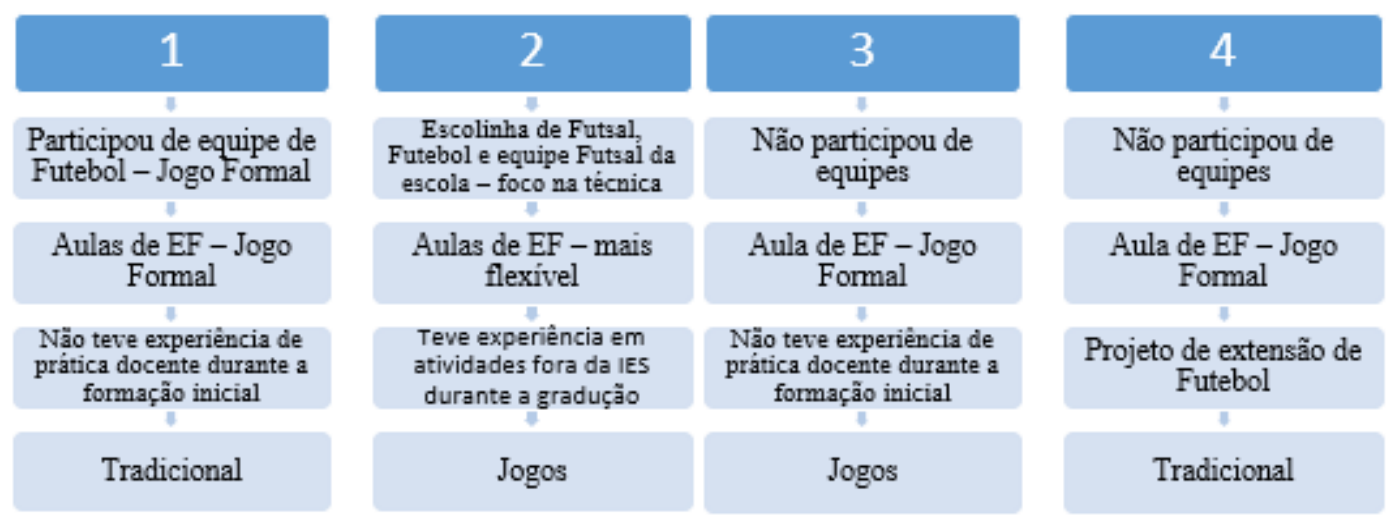

Fonte: Os autores, 2017.

Diante do exposto, foi possível inferir uma relação entre as estratégias escolhidas pelos estagiários 1A, 2A e 4B e as usadas por seus professores nas aulas de EF na escola, assim como nos treinos de futebol do estagiário 1A (Figura 3). Sob o mesmo ponto de vista, Ramos et al. (2014) verificaram que a participação dos sujeitos da pesquisa em práticas esportivas e nas aulas de EF contribuiu para que adquirissem experiências e crenças sobre o ensino dos EC que surgiam conforme eles enfrentavam situações de ensino. Gariglio (2011) aponta o mesmo: essa experiência parece ser fundamental para a organização da intervenção pedagógica do sujeito da pesquisa. Sobre isso, Borges aponta:

[...] antes mesmo de começar sua formação profissional, os futuros docentes de educação física adquirem ao longo de sua trajetória de vida pré-profissional uma bagagem de experiências, de certezas e de crenças a partir da qual é construída uma primeira fonte dos saberes relativos à profissão de educador físico (BORGES, 2005, p. 174).

Os conhecimentos advindos do ambiente escolar são também considerados por Tardif (2010) como saberes interiorizados pelos professores em sua intervenção, assim como aqueles saberes pessoais provenientes da história de vida (participação em equipes e escolinhas), pois muito do que os docentes sabem sobre como ensinar vem dessas fontes, já que durante muitos anos estiveram dentro do seu local de trabalho, a escola, ou, no caso dos professores de EF, em contextos de prática esportiva.

Além dessas experiências pré-formação profissional, ainda é possível a ocorrência de experiências de estágio docente durante a formação inicial, como no caso do estagiário 2A. Foram constatadas em sua fala algumas certezas sobre o ensino dos EC, adquiridas durante esses momentos.

\footnotetext{
Por exemplo, já tentei fazer treinamento de Futsal, tipo, simplesmente voltado para circuito, tá. Circuito, tu faz o circuito, só que simplesmente tu não bota competição no circuito, o aluno já não faz o circuito do mesmo jeito. [...] Os alunos quando eles são pequenos, eles adoram, mas quando eles estão maiorzinhos, já parece que não faz muito sentido. Aí ao invés de tu fazer um circuito, tu faz dois, divide a turma em dois, para ver quem termina primeiro, muda completamente a atividade.
}

Borges (2005, p. 182), quando relata sobre trabalhos realizados com quatro docentes de $\mathrm{EF}$, percebe que todos eles atribuem às experiências práticas vividas durante a graduação o aprendizado da profissão: "são essas experiências práticas que asseguram a ponte entre os conhecimentos aprendidos na universidade e o próprio ensino". O currículo para a formação de professores tem uma primeira parte mais teórica e uma segunda mais prática (estágios supervisionados), como se ele devesse aprender os conhecimentos para posteriormente aplicá- 
los. A prática pedagógica realizada desde o início da graduação, e não apenas ao final dela, facilita para que o aluno faça essa ponte entre os conhecimentos teóricos e a prática docente e vice-versa. A prática deve ser considerada um local de produção e formação de saberes utilizados pelos professores em sua prática docente (TARDIF, 2010; BORGES, 2005).

Além disso, os saberes experienciais dos professores não estão apoiados somente na sua prática, decorrem também das experiências escolares, familiares e sociais que modelam as suas representações e convicções sobre o ensino e a aprendizagem, o papel do professor e a visão sobre o aluno (TARDIF, 2010). Ou seja, a prática como docente não trará somente conhecimentos novos e diferentes daqueles vivenciados durante a escolarização, mas será influenciada por esses saberes prévios que também serão avaliados e filtrados:

\begin{abstract}
A experiência provoca, assim, um efeito de retomada crítica (retroalimentação) dos saberes adquiridos antes ou fora da prática profissional. Ela filtra e seleciona os outros saberes, permitindo assim aos professores reverem seus saberes, julgá-los e avaliá-los e, portanto, objetivar um saber formado de todos os saberes retraduzidos e submetidos ao processo de validação constituído pela prática cotidiana (TARDIF, 2010, p.53).
\end{abstract}

\title{
Conclusão
}

As estratégias de ensino dos EC variaram entre o método tradicional e uma abordagem mais condizente com os propósitos educacionais atuais, a partir da utilização de jogos. De fato, é possível notar uma mudança na maneira como são propostas as aulas de EF para o ensino dos EC.

Foi possível perceber que o conhecimento utilizado pelos estudantes durante o estágio teve influência dos momentos vividos por eles até então: família, treinos, aulas de EF, disciplinas, projetos de extensão e locais de trabalho.

A universidade dificilmente irá modificar o que foi adquirido anteriormente, e o conhecimento se mantém estável durante a formação profissional (TARDIF, 2010; BORGES, 2005; GARIGLIO, 2011). Em virtude disto, os professores universitários devem utilizar o conhecimento que o aluno traz propondo situações semelhantes às das aulas de EF, por exemplo, para que possam modificar suas crenças sobre o ensino dos EC através da análise crítica e da reflexão (RAMOS et al.,2014).

Por outro lado, apesar do número limitado de sujeitos, a presente pesquisa sugere que as disciplinas vinculadas ao ensino de EC e as experiências de prática docente parecem auxiliar na ressignificação dos saberes produzidos nas experiências pré-profissionais, no caso deste estudo, nas estratégias de ensino dos EC utilizadas pelos estagiários. Portanto, estas podem ser outra forma de contribuir para a superação do modelo tradicional de ensino dos EC.

\section{Referências}

AMADO, J.; VEIGA SIMÃO, M. Pensar em voz alta, autoscopia e estimulação da recordação. In: AMADO, J. (Org.). Manual de investigação qualitativa em educação. Coimbra: Imprensa da Universidade de Coimbra, 2013. p. 235-244.

BARDIN, L. Análise de conteúdo. Lisboa: Edições 70, 1977.

BORGES, C. A formação dos docentes de Educação Física e seus saberes profissionais. In: BORGES, C.; DESBIENS, J. (Org.). Saber, formar e intervir para uma educação física em mudança. Campinas, SP: Autores Associados, 2005. p. 158-190. 
COSTA, L.C.A.; NASCIMENTO, J.V. O ensino da técnica e da tática: novas abordagens metodológicas. Revista da Educação Física, Maringá, v. 15, n. 2, p. 49-56, 2.sem., 2004.

Prática pedagógica de professores de Educação Física: conteúdos e abordagens pedagógicas. Revista da Educação Física, Maringá, v. 17, n. 2, p. 161-167, 2. sem., 2006.

DIETRICH, K.; DÜRRWÄCHTER, G.; SCHALLER, H. J. Os grandes jogos: metodologia e prática. Tradução de Renate Sindermann. Rio de Janeiro: Ao Livro Técnico, 1984.

FERREIRA, H. B.; GALLATI, L. R.; PAES, R. R. Pedagogia do Esporte: considerações pedagógicas e metodológicas no processo de ensino-aprendizagem do basquetebol. In: PAES, R.R.; BALBINO, H.F. Pedagogia do Esporte: contextos e perspectivas. Rio de Janeiro: Guanabara Koogan, 2005. p. 123-136.

FIGUEIREDO, Z. C. Formação docente em Educação Física: experiências sociais e relação com o saber. Movimento, Porto Alegre, v. 10, n. 1, p. 89-111, jan./abr. 2004.

FORTES, M. O. et al. A Educação Física escolar na cidade de Pelotas-RS: contexto das aulas e conteúdos. Revista da Educação Física, Maringá, v. 23, n. 1, p. 69-78, 1. trim., 2012.

FREIRE JÚNIOR, J. M; MALDONADO, D. T; SILVA, S. A. P. S. Estratégias para ensinar esporte nas aulas de Educação Física: um estudo na cidade de Aparecida/SP. Motrivivência, Florianópolis, v. 29, n. 51, p. 28-46, jul. 2017.

GALATTI, L. R. et al. Pedagogia do Esporte: tensão na ciência e o ensino dos jogos esportivos coletivos. Revista da Educação Física, Maringá, v. 25, n.1, p. 153-162, 1. trim., 2014.

GARIGLIO, J.A. A socialização pré-profissional de um professor de educação física: a experiência no universo esportivo em questão. Pensar a Prática, Goiânia, v. 14, n. 2, p.1-10, maio/ago. 2011.

GIL, A.C. Como elaborar projetos de pesquisa. 4. ed. São Paulo: Editora Atlas S.A, 2002.

GRAÇA, A. Para uma teoria dos jogos desportivos colectivos. In: GRAÇA, A.; OLIVEIRA, J. O ensino dos jogos desportivos. 3. ed. Porto: FCDEFUP, 1998. p.11-25.

GRAÇA, A.; MESQUITA, I. A investigação sobre o ensino dos jogos desportivos: ensinar e aprender as habilidades básicas do jogo. Revista Portuguesa de Ciências do Desporto, v. 2, n. 5, p. 67-79, 2002.

NASCIMENTO, J.V. et al. Formação acadêmica e intervenção pedagógica nos esportes. Motriz, Rio Claro, v. 15, n. 2, p. 358-366, abr./jun. 2009.

PAES, R.R.; MONTAGNER, P.C.; FERREIRA, H.B. Pedagogia do Esporte: iniciação e treinamento em basquetebol. Rio de Janeiro: Guanabara Koogan, 2015.

RAMOS, V.; GRAÇA, A.B.S.; NASCIMENTO, J.V. A representação do ensino do basquetebol em contexto escolar: estudos de caso de formação inicial em Educação Física. Revista Brasileira de Educação Física e Esporte, São Paulo, v. 20, n. 1, p.37-49, jan./mar. 2006. 
RAMOS, V. et al. As crenças sobre o ensino dos esportes na formação inicial em Educação Física. Revista da Educação Física, Maringá, v. 25, n. 2, p. 231-244, 2014.

REVERDITO, R.S.; SCAGLIA, A.J. Pedagogia do Esporte: jogos coletivos de invasão. São Paulo: Phorte, 2009.

SANTANA, W.C. et al. Pedagogia do Esporte: um novo olhar sobre a dimensão técnica no contexto de ensino-treino dos jogos esportivos coletivos. In: NAVARRO, A.C.; ALMEIDA, R.; SANTANA, W.C. Pedagogia do esporte: jogos esportivos coletivos. São Paulo: Phorte, 2015. p. 47-66.

TARDIF, M. Saberes docentes e formação profissional. 11. ed. Petrópolis, RJ: Vozes, 2010.

TARDIF, M.; RAYMOND, D. Saberes, tempo e aprendizagem do trabalho no magistério. Educação \& Sociedade, v. 21, n. 73, p. 209-244, 2000.

THOMAS, J. R.; NELSON, J. K.; SILVERMAN, S. J. Métodos de pesquisa em atividade física. 3. ed. Porto Alegre: ArtMed, 2003.

Recebido em: $13 / 11 / 2017$

Revisado em: 21/05/2018

Aprovado em: 23/08/2018

Endereço para correspondência:

patriciamachadodasilva@hotmail.com

Patricia Machado da Silva

Universidade Federal de Pelotas, Escola Superior de Educação Física

Rua Luís de Camões, 625

Três Vendas

96055-630 - Pelotas, RS - Brasil 